\title{
Pensamento Computacional no Ensino Fundamental I: um estudo de caso utilizando Computação Desplugada
}

\author{
Cláudia Werlich ${ }^{1,3}$, Cristiani Crema ${ }^{1}$, Avanilde Kemczinski ${ }^{1,2}$, Isabela Gasparini ${ }^{1,2}$ \\ ${ }^{1}$ PPGECMT e ${ }^{2}$ PPGCA, Departamento de Ciência da Computação (DCC) \\ Universidade do Estado de Santa Catarina (UDESC) - Joinville, SC - Brasil \\ ${ }^{3}$ Faculdade Anhanguera - Joinville, SC - Brasil \\ \{clawer, crisitani.crema\}@gmail.com, \\ \{avanilde.kemczinski, isabela.gasparini\} @udesc.br
}

\begin{abstract}
A problem in the teaching and learning process is developing students' critical thinking and problem-solving skills. A strategy that has been used is the teaching of Computational Thinking and the Unplugged Computing technique. This article describes a case study carried out in the discipline of Computational Thinking in a private elementary school. The goal of the case study was to stimulate the individual and collaborative logical reasoning through a Unplugged Computing activity. The study was accomplished out in two stages, the first one individually and the second collaboratively. As a result it was identified that the students of the 2 nd. year of elementary school improved their results with group activity.
\end{abstract}

Resumo. Um problema no processo de ensino e aprendizagem é desenvolver o pensamento crítico e a capacidade de resolução de problemas dos estudantes. Uma estratégia que vem sendo utilizada é o ensino do Pensamento Computacional e a técnica de Computação Desplugada. Esse artigo descreve um estudo de caso realizado na disciplina de Pensamento Computacional em uma escola particular de Ensino Fundamental. O objetivo do estudo de caso foi estimular o raciocínio lógico individual e colaborativo por meio de uma atividade da Computação Desplugada. O estudo foi realizado em duas etapas, a primeira de forma individual e a segunda de forma colaborativa. Como resultado foi identificado que os estudantes do $2^{\circ}$. ano do Ensino Fundamental I melhoraram seus resultados com a atividade em grupo.

\section{Introdução}

A lógica está presente em todos os atos do cotidiano. Conforme Riley e Hunt (2014) a lógica permite diferenciar entre o pensamento incorreto e o correto, podendo ser definida como a ciência do pensamento correto. Um dos pressupostos conceituais do Pensamento Computacional, segundo Wing (2016) é estimular o raciocínio lógico na resolução de problemas.

Rodrigues e Sousa (2017) afirmam que é importante desenvolver os fundamentos da computação em crianças que vivem na Era Digital. Oportunizar o desenvolvimento do Pensamento Computacional faz-se necessário, potencializando as competências dos estudantes quanto ao pensamento crítico e a resolução de problemas, segundo Brackmann et al. (2017). O Pensamento Computacional é uma competência de aplicação geral e é importante que o estudante tenha acesso desde as etapas iniciais de formação, conforme 
VII Congresso Brasileiro de Informática na Educação (CBIE 2018)

Anais dos Workshops do VII Congresso Brasileiro de Informática na Educação (WCBIE 2018)

Hinterholz e Santos (2017).

Uma técnica que vem sendo empregada, de acordo com Vieira, Passos e Barreto (2013) é a Computação Desplugada, que possui a finalidade de ensinar conceitos relacionados à Ciência da Computação sem o uso do computador, oportunizando o aprendizado por meio de brincadeiras direcionadas ao conteúdo previamente proposto

Essa técnica, além de estimular o Pensamento Computacional, permite assimilar fundamentos da Ciência da Computação. Brennan e Resnick (2012) afirmam que um enfoque baseado em Pensamento Computacional pode ser utilizado no aprendizado de programação, principalmente para crianças e adolescentes, desde que seja utilizado ferramentas que motivem e estimulem a inventividade. Conforto el al (2018) afirma que as novas habilidades passam a ser exigidas para viver em um mundo pós-industrial marcado por imaginação, criatividade e inovação.

O professor, enquanto mediador do conhecimento, deve diversificar suas estratégias de ensino, tornando suas aulas dinâmicas e atrativas, considerando também o estudante como sujeito ativo no processo de aprendizagem. Freire (1996, p.47) afirma que "ensinar não é transferir conhecimento, mas criar as possibilidades para a sua própria produção ou a sua construção". Costa (2012) alega que cabe ao professor estimular a autonomia dos estudantes criando oportunidades na produção colaborativa, apoiando os processos de negociação de significados e valorizando as diferentes relações que podem ser estabelecidas em salas de aula.

Este artigo descreve um estudo de caso realizado na disciplina de Pensamento Computacional em uma escola particular de Ensino Fundamental I, situada em Joinville, Santa Catarina. O objetivo do estudo de caso foi estimular o raciocínio lógico individual e colaborativo por meio de uma atividade da Computação Desplugada.

Para contextualizar o processo e os resultados encontrados descrevemos a fundamentação teórica na Seção 2. Em seguida, na Seção 3, descrevemos a metodologia aplicada na atividade de estudo de caso. Na Seção 4, mostramos os resultados obtidos. Por fim, realizamos as considerações finais na Seção 5, seguida das referências bibliográficas.

\section{Pensamento Computacional}

O desenvolvimento das habilidades de resolução de problemas e de senso crítico é necessário frente às transformações sociais e a crescente competitividade no mundo atual. A inclusão do Pensamento Computacional no âmbito escolar contribui na vida social e escolar do estudante, pois, a partir do aprimoramento dessa habilidade, ele pode enfrentar seus desafios diários com maior facilidade (Valente, 2016).

Aho (2012) afirma que o Pensamento Computacional consiste na utilização de técnicas envolvendo a Ciência da Computação, com objetivo de solucionar problemas de qualquer área do conhecimento. Para Wing (2006), o Pensamento Computacional abrange um conjunto de aptidões mentais e de raciocínio que ajudam os indivíduos a interagir e saber pensar na resolução de problemas por meio de uma linguagem computacional. Logo, o Pensamento Computacional envolve a resolução de problemas, concepção de sistemas e compreensão do comportamento humano, partindo dos conceitos fundamentais da Ciência da Computação.

O Pensamento Computacional, conforme Blikstein (2008), é saber usar o 
VII Congresso Brasileiro de Informática na Educação (CBIE 2018)

Anais dos Workshops do VII Congresso Brasileiro de Informática na Educação (WCBIE 2018)

computador como instrumento do poder cognitivo e operacional humano, a fim de aumentar nossa produtividade, inventividade e criatividade. As habilidades estimuladas pelo Pensamento Computacional estão inteiramente relacionadas à resolução de problemas, pois envolvem a capacidade de compreender as situações propostas e criar soluções através de modelos matemáticos, científicos ou sociais (Mestre et al., 2015).

\subsection{Computação Desplugada}

A Computação Desplugada é utilizada no ensino de fundamentos da Ciência da Computação, permitindo que o estudante aprenda de maneira concreta e divertida, sem a necessidade de aparatos tecnológicos. Desta forma, leva o conhecimento sobre Ciência da Computação a lugares em que os computadores e suas tecnologias ainda não são realidade (Santos et al. 2016).

As atividades desplugadas estão diretamente conectadas ao Pensamento Computacional, que tende a modificar a forma como os indivíduos (sem limite de idade) resolvem os problemas, contribuindo para a criação de novas ferramentas, uma vez que tais indivíduos tendem a se tornar produtores de tecnologias, despertando o interesse pelo funcionamento da tecnologia e não apenas como meros consumidores.

De acordo com Manhães et al. (2017), a Computação Desplugada tem como foco compreender melhor a tecnologia sem utilizá-la. Nesse processo, o estudante deve pensar como um computador, o que torna a aprendizagem desafiadora e divertida. As atividades desplugadas possibilitam ampliar o conhecimento em relação a tecnologia, mesmo em regiões com falta de recursos tecnológicos.

\subsection{Trabalhos relacionados de atividades desplugadas}

Os trabalhos apresentados nesta seção contemplam atividades desplugadas direcionadas ao Ensino Fundamental I e II.

Scaico (2012), descreve uma experiência realizada por Estagiários da Licenciatura em Computação, com estudantes do Ensino Fundamental do $4^{\circ}, 5^{\circ}$ e $9^{\circ}$ anos, baseada em uma atividade de Bell et al. (2011), intitulada "Contando os Pontos", que objetiva ensinar os números binários. Um problema era que os estudantes do $4^{\circ}$ e $5^{\circ}$ anos, não conseguiam compreender o significado do " 0 " e do "1" em posições diferentes. Visando facilitar o entendimento, os autores adaptaram seu trabalho, trocando a figura do "0" por uma lâmpada apagada, e a figura do "1" por uma lâmpada acesa. A análise da atividade ocorreu mediante uma avaliação em que os estudantes fizeram a conversão de números decimais em sequências binárias correspondentes, com propósito de mensurar a aprendizagem dos estudantes. Diante das análises dos dados coletados o autor conclui que a atividade é mais adequada para estudantes do $5^{\circ}$ ano.

Oliveira et al. (2014) trata do resultado de um projeto de extensão no qual um curso com foco em lógica de programação foi realizado, tendo como objetivo ensinar conceitos básicos, por meio do desenvolvimento de jogos e animações. Utilizaram o Scratch e Computação Desplugada como instrumento para desenvolver e compreender algoritmos. A aplicação foi realizada em uma escola pública, abrangendo 20 estudantes do Ensino Fundamental do $9^{\circ}$ ano. As atividades desplugadas realizadas foram: contando os pontos (números binários), programado para dançar (algoritmos e instruções) e seguindo instruções (linguagens de programação), com base em Bell et al. (2011). Durante o processo de aplicação das atividades, os estudantes foram avaliados por meio 
VII Congresso Brasileiro de Informática na Educação (CBIE 2018)

Anais dos Workshops do VII Congresso Brasileiro de Informática na Educação (WCBIE 2018)

de questionários e entrevistas. Os resultados obtidos evidenciaram que os estudantes tiveram entendimento sobre os conceitos abordados e demostraram interesse na realização das atividades.

Costa et al. (2012) descreve uma gincana com participação de 64 estudantes do $9^{\circ}$ ano do Ensino Fundamental de uma instituição de ensino privada. Foram aplicadas quatro atividades desplugadas com base em Bell et al. (2011), abordando os fundamentos da computação: jogo da laranja (roteamento e bloqueio de redes), cidade enlameada (árvores geradoras mínimas), caça ao tesouro (autômatos de estados finitos) e seguindo instruções (programação). Na gincana percebeu-se o interesse dos estudantes em participar e a cooperação no trabalho em equipe, resultando no interesse da instituição de ensino continuar com o trabalho envolvendo outras turmas.

Santos et al. (2015), propõe uma atividade direcionada ao $5^{\circ}$ ano do Ensino Fundamental utilizando a Computação Desplugada, com objetivo de potencializar habilidades do Pensamento Computacional por meio do ensino de algoritmos. O autor teve como ponto de partida a ferramenta Scratch para criar a atividade desplugada, baseando-se no modo de construção de algoritmos, que utiliza blocos de borracha em EVA (Etil Vinil Acetato) de cores e tamanhos distintos. Na execução dos algoritmos foram utilizados tabuleiros impressos no tamanho A4, além de itens coletáveis e desafios. As atividades de algoritmos desplugadas tiveram como objetivo ensinar as estruturas básicas de programação, como: repetição e decisão, através de algoritmos. A avaliação acontece por meio da aplicação de um teste com questões dissertativas (70\%) abordando os conceitos trabalhados e participação $(30 \%)$ de cada estudante.

Brackmann et al. (2017) apresenta o relato de uma experiência envolvendo 72 estudantes dos $5^{\circ}$. e $6^{\circ}$. anos do Ensino Fundamental. $\mathrm{O}$ objetivo dessa proposta foi oportunizar o ensino do Pensamento Computacional por meio de atividades desplugadas, visto que as duas escolas onde ocorreram as aplicações não possuíam recursos tecnológicos. Foram aplicadas seis atividades abordando conceitos da Ciência da Computação: Decomposição (reconhecimento de padrões e algoritmos); Tetris1 Instruções Simples (abstração e algoritmos); Tetris2 - Repetição (decomposição; abstração; reconhecimento de padrão e algoritmos); Os Elefantes (decomposição, abstração e algoritmos) e Rota de fuga do Cebolinha e Cascão (decomposição, abstração e algoritmos). A avaliação foi realizada por meio de um questionário com 28 questões de múltipla escolha, abordando os quatro pilares do Pensamento Computacional: abstração, decomposição, reconhecimento de padrões e algoritmos. Com base nos resultados estatísticos apresentados pelos autores é possível observar melhora no rendimento dos estudantes após a aplicação dessas atividades.

A atividade de Caça ao Tesouro de Costa et al. (2012), foi aplicada durante a gincana com os estudantes do $9^{\circ}$ ano do Ensino Fundamental. O desafio consistia em encontrar o menor caminho durante o percurso. A atividade baseada em Bell et al. (2011), necessitou de algumas adaptações como: aumento do número de nós no mapa para aumentar a complexidade e a atividade foi realizada paralelamente entre as equipes. $\mathrm{O}$ maior valor de pontuação era atribuído à equipe que encontrasse o caminho em menor tempo.

Um trabalho similar foi o de Brackmann et al. (2017), que propôs atividades Mapa da Mônica e Rota de fuga do Cebolinha e Cascão, para os estudantes dos $5^{\circ}$. e $6^{\circ}$. anos. Nessa atividade os estudantes receberam um mapa com diversos personagens da Turma 
VII Congresso Brasileiro de Informática na Educação (CBIE 2018)

Anais dos Workshops do VII Congresso Brasileiro de Informática na Educação (WCBIE 2018)

da Mônica e tinham como desafio encontrar o caminho mais curto entre eles, utilizando setas $(\uparrow, \downarrow, \leftarrow \mathrm{e} \rightarrow)$. Em seguida, deveriam encontrar os padrões e usar multiplicadores $(\uparrow \uparrow \uparrow \uparrow \uparrow=5 \mathrm{x} \uparrow)$. Esses dois últimos trabalhos relacionados assemelham-se à aplicação da proposta "Mapa Náutico" apresentada nesse artigo, porém, o diferencial deste trabalho está na aplicação ao Ensino Fundamental I.

Visando fomentar o Pensamento Computacional para estudantes do Ensino Fundamental I, o presente artigo apresenta um estudo de caso utilizando a aplicação de atividades desplugadas nas aulas de Pensamento Computacional.

\section{Metodologia}

Com o objetivo de estimular e verificar o raciocínio lógico dos estudantes da disciplina de Pensamento Computacional, foi elaborado, aplicado e analisado um desafio utilizandose da técnica de Computação Desplugada. O objetivo foi verificar como os estudantes iriam aplicar a lógica para a resolução da situação-problema e comparar os resultados da atividade individual com o trabalho em equipe.

Participaram da atividade um total de 32 estudantes da disciplina curricular de Pensamento Computacional de uma escola da rede particular do Ensino Fundamental I de Joinville, Santa Catarina. A atividade proposta foi aplicada pela coautora do artigo e professora da disciplina. As duas turmas do $1^{\circ}$ ano e do $2^{\circ}$ ano do Ensino Fundamental I eram compostas de 23 meninos e 9 meninas com idades entre 6 e 8 anos.

\subsection{Atividade Proposta}

A atividade aplicada tem como objetivo principal encontrar o caminho utilizando a quantidade mínima de retângulos (referenciando o clássico problema de caminho mínimo). A atividade consiste em "recolher" 10 objetos "perdidos" pelo pirata e estabelecer a melhor rota (traçando uma linha), desviando de diversos obstáculos. Cada estudante recebeu um Mapa Náutico, conforme a Figura 1.

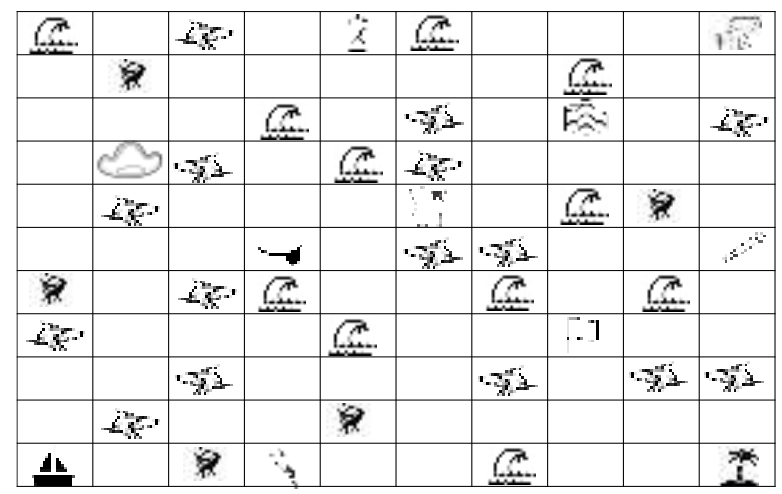

Figura 1. Mapa Náutico

Para contextualizar a atividade proposta e devido a faixa etária dos estudantes foi criado uma história introdutória, conforme o Quadro 1 e que foi dramatizada pela docente da disciplina de Pensamento Computacional. 
VII Congresso Brasileiro de Informática na Educação (CBIE 2018)

Anais dos Workshops do VII Congresso Brasileiro de Informática na Educação (WCBIE 2018)

Um pirata desastrado em sua viagem acabou esquecendo seus objetos mais
importantes. Ficou somente com o seu barquinho, e mais nada! Você precisará
ajudar o pirata a encontrar seu itens preciosos. Observe na folha os objetos
esquecidos pelo pirata, você consegue identificar? Existem terríveis obstáculos
nesta missão que precisam ser desviados. Quais são os obstáculos encontrados
nos retângulos? Você precisará achar um caminho mais rápido e seguro para
conseguir pegar todos os objetos.

Ao contar a história introdutória foi necessário um reforço no significado da palavra obstáculo, pois vários estudantes do $1^{\circ}$ ano não sabiam seu significado. Assim que foi informado que a palavra estava se referindo a "um perigo do mar", todos apontaram os perigos no mapa. Com o entendimento da história, as regras da atividade foram estabelecidas:

- O ponto inicial da atividade deverá ser no canto inferior a esquerda do mapa, com a imagem do navio;

- Todo obstáculo precisa ser evitado, não é permitido passar por cima dele;

- Um retângulo poderá ser utilizado mais de uma vez (o estudante poderá voltar no retângulo caso desejar, mas a linha deverá ser paralela, para facilitar a contagem).

- O sentido da linha pode ser: para frente, para atrás, para a esquerda ou para a direita;

- Não é permitido linhas diagonais, para abreviar o caminho.

No primeiro momento, a atividade foi realizada de forma individual, cada estudante recebeu um Mapa Náutico e anotou seu nome, em seguida fez uma linha, ligando o barco com os objetos perdidos, sempre desviando dos obstáculos.

$\mathrm{Na}$ segunda etapa, os estudantes formaram equipes de quatro integrantes. Cada estudante contou e anotou a quantidade de retângulos utilizados para pegar os objetos. Para verificar se a contagem individual foi realizada corretamente, a primeira missão da equipe foi realizar a recontagem para saber qual integrante utilizou o menor caminho. Após, receberam um único Mapa Náutico e em grupos tiveram a missão de diminuir a quantidade de retângulos percorridos para diminuir ainda mais o caminho, para pegar os objetos esquecidos, isto é encontrar o caminho mais curto e mais rápido.

\subsection{Coleta de dados - Observação direta}

Para realizar a coleta dos dados definimos algumas questões para nos auxiliar a responder a análise individual da atividade proposta: (1) Qual a quantidade mínima e máxima de retângulos encontrados pelos estudantes? (2) Quantos estudantes conseguiram a quantidade mínima e máxima de retângulos utilizados? (3) Quantos estudantes ignoram o obstáculo, abreviando o caminho, passando uma linha por cima do obstáculo? (4) Houve algum estudante que não encontrou um determinado objeto? (5) Quantos estudantes não conseguiram traçar uma linha contínua e acabaram se perdendo no caminho?.

Para analisar o trabalho em equipe foram utilizadas as seguintes questões: (6) Quantas equipes melhoraram a quantidade de retângulos em relação a primeira etapa (individual)? Otimizaram o caminho ou optaram pela caminho encontrado previamente? (7) Quantas equipes pioraram a quantidade de retângulos em relação a primeira etapa (individual)? (8) Como foi o processo de discussão e negociação das equipes? Conseguiram conciliar na equipe ou houve necessidade de intervenção do professor?. 
VII Congresso Brasileiro de Informática na Educação (CBIE 2018)

Anais dos Workshops do VII Congresso Brasileiro de Informática na Educação (WCBIE 2018)

\section{Resultados}

Um total de 32 estudantes participaram das atividades individuais, e na etapa em grupo 8 equipes de quatro integrantes foram formadas. $\mathrm{O}$ tempo da atividade foi de 45 minutos para as duas turmas. Esta seção apresenta o resultado de cada questão observada.

\section{1 Resultados Individuais}

A realização individual da atividade ocorreu de forma idêntica nas duas turmas. Ao receber o mapa os estudantes ficaram sem saber o que fazer e com muita curiosidade. A quantidade de objetos dispostos no Mapa Náutico não possibilitou uma rápida dedução do que se tratava a atividade. Os estudantes escutaram atentamente as instruções e logo começaram a realizar a atividade com muito interesse e velocidade (em nenhum momento foi estipulado o tempo da tarefa).

A Q1: "Qual a quantidade mínima e máxima de retângulos encontrados pelos estudantes?" foi utilizada para verificar o caminho mais curto e o mais longo. A grande maioria dos estudantes utilizou entre 64 e 74 retângulos. A quantidade mínima foi de 60 retângulos e demonstra o caminho mais curto encontrado pelos estudantes. A quantidade máxima foi de 97 retângulos, determinando o caminho mais longo na busca dos objetos perdidos, conforme a Figura 2.

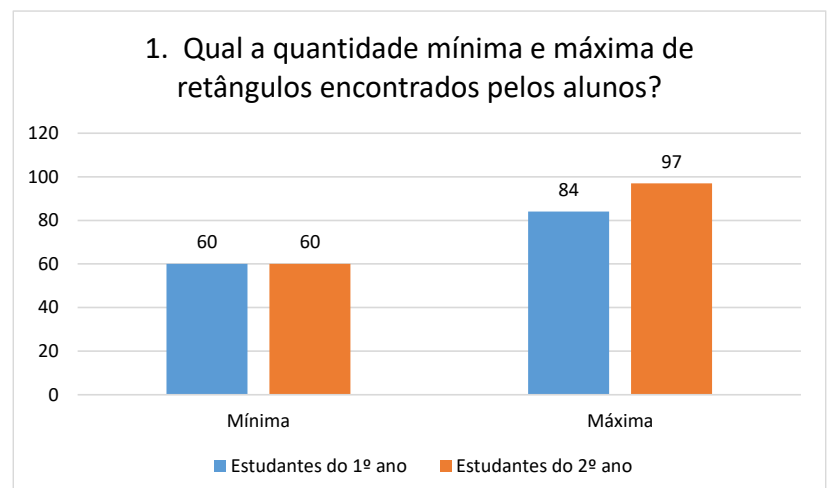

Figura 2. Número de retângulos encontrados para cada turma do Ensino Fundamental I

Para a Q2: “Quantos estudantes conseguiram a quantidade mínima e máxima de retângulos utilizados?", dos 32 estudantes, 7 estudantes (4 estudantes do $1^{\circ}$ ano e 3 estudantes do $2^{\circ}$. ano) conseguiram encontrar o menor caminho, utilizando 60 retângulos. Esses dados são apresentados na Figura 3.

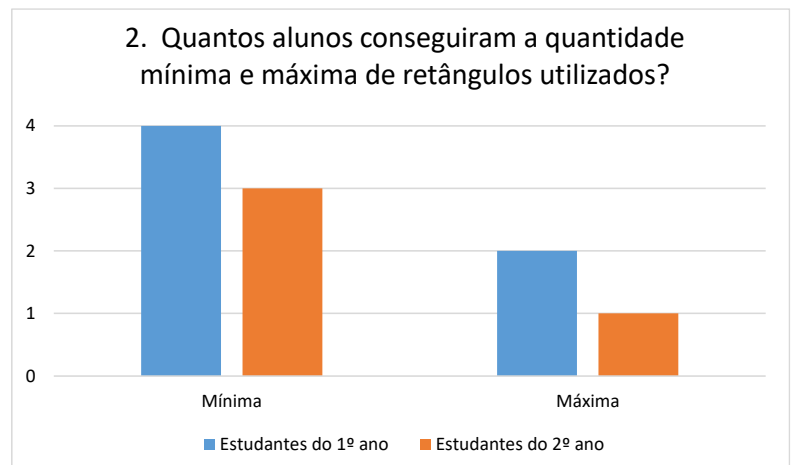

Figura 3. Desempenho dos Estudantes no Menor e Maior Caminho 
Quanto a Q3: "Quantos estudantes ignoram o obstáculo, abreviando o caminho, passando uma linha por cima do obstáculo?" percebe-se que somente os estudantes do $1^{\circ}$ ano tiveram problemas com a regra imposta. Foram 5 estudantes, todos do $1^{\circ}$ ano, que ignoraram as regras e passaram por cima dos obstáculos. Uma justificativa quanto a esta questão pode estar relacionada com a idade dos estudantes.

A Q4: "Houve algum estudante que não encontrou um determinado objeto?" revelou que 4 estudantes não encontram todos os objetos. Mais especificamente 1 estudante do $2^{\circ}$ ano não encontrou o papagaio e 3 estudantes do $1^{\circ}$ ano não pegaram o chapéu do pirata.

Um total de 53\% dos estudantes não conseguiu traçar um caminho lógico, a Q5: "Quantos estudantes não conseguiram traçar uma linha contínua e acabaram se perdendo no caminho?" demonstrou que 8 estudantes do $1^{\circ}$ ano e 9 estudantes do $2^{\circ}$ ano, ficaram confusos e o caminho foi interrompido ou abandonado. Para verificar se este problema poderia ser melhorado com o trabalho em equipe a segunda etapa do estudo de caso foi a composição das equipes e a continuidade do trabalho.

\section{2 Resultados em Equipes}

Quanto a Q6: “Quantas equipes melhoraram a quantidade de retângulos em relação a primeira etapa (individual)? Otimizaram o caminho ou optaram pelo caminho encontrado previamente?" percebeu-se que o trabalho em equipe possibilita uma melhor tomada de decisão na otimização do menor caminho. Todas as equipes da turma do $2^{\circ}$ ano melhoraram seu desempenho diminuindo o caminho, 2 equipes fizeram um novo trajeto e outras 2 somente otimizaram o caminho (analisando cuidadosamente o trajeto de cada integrante para determinar o melhor caminho). Na turma do $1^{\circ}$ ano somente 2 equipes conseguiram diminuir a quantidade de retângulos para diminuir o caminho, mas não utilizaram um novo trajeto. Devido a conflitos internos na equipe, duas equipes não conseguiram terminar a tarefa (sequer terminaram de traçar o percurso) piorando as marcas individuais.

O resultado da Q7: "Quantas equipes pioraram a quantidade de retângulos em relação a primeira etapa (individual)?" demonstrou que o $1^{\circ}$ ano não obteve êxito no trabalho em equipe, pois 2 equipes (50\% da turma) não conseguiram terminar a tarefa. A Q8: "Como foi o processo de discussão e negociação das equipes? Conseguiram conciliar na equipe ou houve necessidade de intervenção do professor?" justifica a QP7. Devido a conflitos em uma equipe do $1^{\circ}$ ano, houve a necessidade de mediação do professor em 2 momentos para evitar confusão. Na outra equipe do $1^{\circ}$ ano, que apresentou um desempenho pior, dois estudantes se recusaram a participar da atividade em equipe, pois queriam fazer a atividade sozinhos. Esse comportamento pode ser explicado, conforme Piaget (1991) a criança pode estar no período pré-operatório e este período é caracterizado pela inteligência simbólica, tendo como uma característica importante o egocentrismo. Nesta fase a criança não consegue imaginar uma realidade da qual não faça parte dela.

\section{Considerações Finais e Trabalhos Futuros}

Neste trabalho buscou-se a verificação do entendimento do estudante na aplicação da lógica do Pensamento Computacional com uma atividade da Computação Desplugada. A atividade proposta buscou verificar o desempenho do estudante frente a um desafio desconhecido e inesperado. Ao realizar a atividade percebeu-se que os estudantes foram 
VII Congresso Brasileiro de Informática na Educação (CBIE 2018)

Anais dos Workshops do VII Congresso Brasileiro de Informática na Educação (WCBIE 2018)

muito afoitos e não pensaram primeiro, já foram logo ligando os retângulos para encontrar os objetos, o que ocasionou muitos caminhos desconexos. Esse fato se comprova, pois ao término da atividade, os estudantes foram questionados sobre a quantidade de objetos que precisavam pegar e somente 2 estudantes (do 1 ano) dos 32 estudantes contaram e sabiam que eram 10 objetos.

O trabalho em equipe na turma do $2^{\circ}$ ano permitiu uma eficiência tanto na quantidade menor de retângulos utilizados, quanto da otimização do caminho. Na turma do $1^{\circ}$ ano o trabalho em equipe se revelou um grande problema para a maioria dos estudantes, que não souberam escutar os colegas ou dividir as tarefas.

O resultado da diferença do desempenho entre o trabalho individual e em equipes nas atividades de Pensamento Computacional pode ser um alvo de estudos futuros. Podese investigar a relação das faixas etárias e desempenho individual e em equipe. Como trabalho futuro esta pesquisa irá investigar novas estratégias da Computação Desplugada e do Pensamento Computacional para aplicação em estudantes de diferentes faixas etárias e em diferentes escolas. Espera-se que estas ações possam contribuir para a melhoria do pensamento crítico e da resolução de problemas, além de aumentar seus entendimentos sobre a área da Computação.

\section{Agradecimentos}

Este trabalho foi realizado com o apoio da FAPESC - Termo de Outorga $n^{\circ}$ 2017TR649 - Processo 531/2017.

\section{Referências}

Aho, A. V. (2012) Computation and Computational Thinking. The Computer Journal, [s.1.], v. 55, n. 7, p.832-835. Oxford University Press (OUP). Disponível em: $<$ https://bit.ly/2ODFd3w >. Acesso em: 15 set. 2018.

Bell, T., Witten, I, H. e Fellows M. (2011). Computer Science Unplugged: Ensinando Ciência da Computação sem o uso do computador. Tradução coordenada por Luciano Porto Barreto.

Blikstein, P. (2008). O pensamento computacional e a reinvenção do computador na educação. Disponível em <http://www.blikstein.com/paulo/documents/online /ol_pensamento_computacional.html> Acesso em: 22 de set. de 2018.

Brackmann, C. et al. Pensamento Computacional Desplugado: Ensino e Avaliação na Educação Primária Espanhola. In: Anais dos Workshops do VI Congresso Brasileiro de Informática na Educação. SBC, 2017.

Brennan, K. e Resnick, M. (2012). New frameworks for studying and assessing the development of computational thinking. In Proceedings of the 2012 annual meeting of the American Educational Research Association, Vancouver, Canadá.

Conforto, D., Cavedini, P., Miranda, R., \& Caetano, S. (2018). Pensamento computacional na educação básica: interface tecnológica na construção de competências do século XXI. Revista Brasileira de Ensino de Ciências e Matemática.

Costa, F. A. et al. (2012) Repensar as TIC na educação: O professor como agente transformador. Carnaxide: Santillana. Disponível em: < https://bit.ly/2pkNgHn $>$. Acesso em: 15 set. 2018. 
VII Congresso Brasileiro de Informática na Educação (CBIE 2018)

Anais dos Workshops do VII Congresso Brasileiro de Informática na Educação (WCBIE 2018)

Freire, Paulo. Pedagogia da Autonomia. Saberes necessários à prática educativa. São Paulo: Paz e Terra, 1996. 148p.

Hinterholz, L., dos Santos, W. O. (2017). Aprendizagem Baseada em Projetos: Relato de Introdução da Lógica no Ensino Fundamental. In Anais do Workshop de Informática na Escola (Vol. 23, No. 1, p. 1154).

Manhães, T. S.; Gonçalves, F. S.; Cafezeiro, I. Computação Desplugada e Educada. VII Esocite, p.1-25, 2017.

Mestre, P., Andrade, W., Guerrero, D., Sampaio, L., da Silva Rodrigues, R. e Costa, E. (2015) Pensamento Computacional: Um estudo empírico sobre as questões de matemática do PISA. In: Anais dos Workshops do Congresso Brasileiro de Informática na Educação. p. 1281.

Oliveira, M. L. S. et al. Ensino de lógica de programação no ensino fundamental utilizando o Scratch: um relato de experiência. In: Anais do Workshop de Informática na Escola, Brasília-DF. 2014.

Piaget, J. A epistemologia genética e a pesquisa psicológica. Rio de Janeiro: Forense, 1991.

Reis, F. M. et al. Pensamento Computacional: Uma Proposta de Ensino com Estratégias Diversificadas para Crianças do Ensino Fundamental. In: Anais do XXIII Workshop de Informática na Escola. SBC, 2017.

Riley, D. D.; Hunt, K. A. Computational thinking for the modern problem solver. Boca Raton, FL: CRC Press Book, 2014.

Rodrigues, G., Sousa, L. (2017) . O ensino do pensamento computacional como forma de inclusão tecnológica e motivação de crianças. In Brazilian Symposium on Computers in Education (Simpósio Brasileiro de Informática na Educação-SBIE) (Vol. 28, No. 1, p. 1784).

Santos, E. R. et al. (2016) Estímulo ao Pensamento Computacional a partir da Computação Desplugada: uma proposta para Educação Infantil. Revista Latinoamericana de Tecnología Educativa, Porto Alegre, v. 15, p.99-112, Semestral. Disponível em: < https://bit.ly/2pkOFh7>. Acesso em: 15 set. 2018.

Santos, G. et al. Proposta de atividade para o quinto ano do ensino fundamental: Algoritmos Desplugados. In: Anais do XXI Workshop de Informática na Escola (wie 2015), p.246-255, 26 out. 2015. Sociedade Brasileira de Computação - SBC.

Scaico, P. D. et al. (2012) Um Relato de Experiências de Estagiários da Licenciatura em Computação com o Ensino de Computação para Crianças. Novas Tecnologias na Educação: CINTED, Rio Grande do Sul, v. 10, n. 3, p.1-10, Semestral. Disponível em: $<$ https://bit.ly/2DgnNJ4>. Acesso em: 15 set. 2018.

Valente, J. A. (2016). Integração do Pensamento Computacional no Currículo da Educação Básica: diferentes estratégias usadas e questões de formação de professores e avaliação do aluno. PUC, São Paulo. Disponível em: $<$ https://bit.ly/2NwQANZ>. Acesso em: 21 set. 2018.

Vieira, A.; Passos, O.; Barreto, R. (2013). "Um Relato de Experiência do Uso da Técnica Computação Desplugada". In: Anais do XXI WEI, p. 670-679.

Wing, J. M. (2006).Computational Thinking. Communications ACM. March, V. 9, N. 13. 